\title{
Prospecção fitoquímica do arilo de sementes de maracujá amarelo e influência em germinação de sementes
}

\author{
Phytochemical screening of the arils of yellow passion fruits seeds and influence on the seed \\ germination
}

\author{
Cristiane Miranda Martins ${ }^{\mathrm{I}}$ Marco Antonio da Silva Vasconcellos ${ }^{\mathrm{I}^{*}}$ \\ Claudia Antonia Vieira Rossetto ${ }^{\mathrm{II}}$ Mario Geraldo de Carvalho ${ }^{\mathrm{II}}$
}

\section{RESUMO}

\begin{abstract}
O maracujazeiro amarelo é propagado por sementes que apresentam problemas na sua germinação devido à presença do arilo que pode conter substâncias inibidoras. $O$ trabalho foi realizado com o objetivo de identificar as classes de metabolitos especiais contidas no arilo das sementes de maracujá amarelo. Para isso, após a extração do arilo das sementes de maracujá amarelo, foram obtidos os extratos de diclorometano e metanol. As classes foram identificadas por meio de prospecção fitoquímica aliada à análise de espectros de infravermelho e ressonância magnética nuclear de hidrogênio $\left(R M N{ }^{1} \mathrm{H}\right)$ de frações dos extratos obtidas com fracionamento em coluna de gel de sílica. Para avaliação da sensibilidade das sementes a essas substâncias, foram instalados testes de germinação com sementes de alface. No extrato de arilo obtido com diclorometano, identificaram-se esteróides e triterpenóides, verificou-se inibição da germinação das sementes. No extrato metanólico, identificaram-se açúcares redutores e verificou-se redução da germinação das sementes.
\end{abstract}

Palavras-chave: Passiflora edulis f.flavicarpa Deg, prospecção fitoquímica.

\section{ABSTRACT}

The passion fruit is propagated by seeds that have problems in their germination due to the presence of aryl which may contain inhibitory substances. The aim of this research was to identify the metabolites classes contained on the aril of yellow passion fruit. For this, after arils extraction, dichlorometane and methanol extracts were obtained. The Classes of metabolites were identified by phytochemical screening coupled with infrared spectroscopy and nuclear magnetic resonance (1H NMR) and extract fractions were obtained by fractionation on a column of silica gel. To evaluate the sensitivity of seeds to these substances, germination tests with lettuce seeds were installed. In aril extract obtained with dichloromethane, steroids and triterpenoids were identified and inhibition of seeds germination observed. In the methanol extract, reducing sugars were found and it was verified reduction of seeds germination.

Key words: Passiflora edulis $f$. flavicarpa, phytochemical prospection.

\section{INTRODUÇÃO}

O maracujazeiro amarelo (Passiflora edulis f. flavicarpa Deg.) é a espécie comercialmente mais cultivada no Brasil, sendo suas mudas obtidas a partir de suas sementes. Contudo, muitos são os aspectos que necessitam de estudos para efetivo êxito da cultura, tais como os relacionados à germinação desuniforme $\mathrm{e}$ irregular, entre outros. MORLEY-BUNKER (1974) atribui a baixa germinação de semente dessa espécie à impermeabilidade do tegumento e ausência ou baixo nível de reguladores de crescimento, que pode influenciar a entrada de água para o interior da semente e condicionar dormência ou germinação, respectivamente. Já GEMMELL (1981) relata que, em frutos suculentos, como os de maracujá, as sementes não germinam dentro do fruto, devido à presença de inibidores da germinação. Para CARVALHO \&

'Programa de Pós-graduação em Fitotecnia, Universidade Federal Rural do Rio de Janeiro (UFRRJ), Seropédica, RJ, Brasil. "Departamento de Fitotecnia, Instituto de Agronomia, UFRRJ, 23890-000, Seropédica, RJ, Brasil. E-mail: masv@ufrrj.br.*Autor para correspondência

II'Departamento de Química, Instituto de Ciências Exatas, UFRRJ, Seropédica, RJ, Brasil. 
NAKAGAWA (2000), algumas substâncias que inibem o processo germinativo podem se concentrar em tecidos que recobrem as sementes ou em camadas do fruto. Em Passifloraceae, PEREIRA \& DIAS (2000) constataram que o arilo, o qual consiste em capa de constituição gelatinosa rica em pectina, prejudicou a uniformidade da germinação por atuar como barreira ou conter substâncias reguladoras de crescimento.

Além disso, em outras espécies que possuem mucilagem envolvendo suas sementes, também foram constatados problemas relacionados à germinação. Em mamoeiro, GHERARDI \& VALIO (1975) reportaram que, na sarcotesta, estrutura semelhante ao arilo, há giberelinas, citocininas e alguns inibidores. Esses autores observaram ainda que extratos à base da sarcotesta inibiram a germinação de sementes de alface, tomate, cenoura e do próprio mamão. Para REYES et al. (1980), o inibidor de crescimento presente na semente de mamão é conhecido como caricacina. Também em café PEREIRA et al. (2002) constataram que o endosperma é constituído de células esclerenquimatosas e formado a partir de células remanescentes do tecido nucelar, que pode contribuir para a lenta germinação das sementes, possivelmente devido à presença de cafeína.

Dentro desse contexto, com o objetivo principalmente de proporcionar emergência de plântulas mais rápida e uniforme, recomenda-se a remoção do arilo de passifloráceas. Isso pode ser feito por vários métodos (SÃO JOSÉ \& NAKAGAWA, 1987; CARDOSO et al., 2001; LOPES et al., 2007); porém, faltam informações relevantes sobre as classes de substâncias contidas no arilo e a possível influência dessas substâncias na germinação, permitindo auxiliar no processo de extração e preparo das sementes, bem como aperfeiçoar as técnicas empregadas na produção de mudas a partir de sementes. Assim, o objetivo do trabalho foi identificar as classes de substâncias presentes no arilo de sementes de maracujazeiro amarelo.

\section{MATERIAL E MÉTODOS}

A pesquisa iniciou-se com a extração do arilo das sementes de maracujazeiro amarelo, provenientes de frutos selecionados em relação ao tamanho (calibre 12) e ao estágio de maturação (de vez). O suco foi retirado por meio de leve compressão das sementes com peneira de malha fina, e as sementes, juntamente com o arilo, foram lavadas com jato d'água e transferidas para papel toalha, onde permaneceram durante quatro dias sob condições de temperatura e umidade relativa do ar não controladas (SÃO JOSÉ \& NAKAGAWA,
1987). Após esse período, o arilo foi retirado por meio de leve fricção entre as mãos, sendo acondicionado em saco de papel e mantido em câmara sob temperatura de $18 \pm 2^{\circ} \mathrm{C}$. Posteriormente, 20,65g de arilo foram acondicionados em recipiente de vidro e submetidos à extração por meio de maceração contínua, sendo utilizados dois solventes orgânicos, diclorometano e metanol, nessa ordem de polaridade. Os extratos foram concentrados em evaporador rotativo sob pressão reduzida e, após evaporação do solvente sob ação de ar quente, foram obtidos os resíduos (extratos brutos): $0,390 \mathrm{~g}$ de AD (extrato de arilo com diclorometano) e 13,0g de AM (extrato de arilo com metanol).

Os resíduos foram divididos em duas porções: a primeira $(0,210 \mathrm{~g})$, para os testes de sensibilidade, e a segunda, para o fracionamento por meio de cromatografia em coluna. Para isso, foi utilizada como adsorvente sílica gel 60 Fluka, e 230-400 mesh, diclorometano, acetato de etila e metanol foram utilizados como eluentes, nessa ordem de polaridades. Desse modo, as seguintes frações foram obtidas: diclorometano (ADD e AMD), acetato de etila (ADA e AMA), metanólico (ADM e AMM). Esse fracionamento foi realizado para facilitar as análises espectrométricas. Nos extratos, foi avaliada a presença de classes das substâncias: alcaloides, esteroides e triterpenoides, flavonoides e ácidos orgânicos, de acordo com metodologia descrita por WALL (2006), e saponinas (MATOS, 1997), depsídios e depsidonas, catequinas, derivados de cumarina, açúcares redutores e polissacarídios, de acordo com metodologia descrita por COSTA(1972).

Visando a confirmar os resultados obtidos com a prospecção química dos extratos, registraram-se espectros de ressonância magnética nuclear de hidrogênio $\left(\mathrm{RMN}{ }^{1} \mathrm{H}\right)$ de frações dos extratos em espectrômetro Ac-200E da Bruker (200MHz para hidrogênio). As frações foram dissolvidas em clorofórmio deuterado $\left(\mathrm{CDCl}_{3}\right)$ ou metanol deuterado (MeOD ), dependendo da polaridade de cada fração, e colocadås em tubos de vidro $(15 \times 0,5 \mathrm{~mm})$. A escala de deslocamento químico foi expressa em ppm $(\delta)$, usando como padrão o TMS $(0,0 \delta)$. Os espectros foram então analisados qualitativamente e observados os sinais compatíveis com substâncias pertencentes às respectivas classes detectadas ou não pela via química (BÔCKER, 1997). Também foram analisados os espectros obtidos no infravermelho (IV) para obter informações adicionais sobre as classes desses metabólitos especiais. Para isso, foram preparados pastilha de $\mathrm{KBr}$, para o material sólido, e filme em $\mathrm{NaCl}$, para o material pastoso. Utilizou-se o espectrofotômetro Perkin Elmer, modelo 1600/1605 FT-IR. 
No teste de sensibilidade, foi utilizado o delineamento inteiramente casualizado, com quatro tratamentos e oito repetições. Para tanto, subamostras de 50 sementes foram distribuídas sobre duas folhas de papel tipo germitest, previamente umedecidas com o extrato de arilo obtidos com diclorometano e com metanol na quantidade equivalente à proporção de 2,5 vezes a massa do papel. Como controle, foi utilizado o umedecimento do papel com água destilada (com e sem tween). No preparo dos extratos, foram utilizados $200 \mathrm{mg}$ do extrato bruto, solubilizados com duas gotas de tween, adicionando água destilada até completar o volume de 30ml. Após a instalação, as sementes foram mantidas no interior de caixas plásticas tipo gerbox, a $20^{\circ} \mathrm{C}$, na presença de luz, durante sete dias. As avaliações foram realizadas aos quatro e sete dias após a instalação do teste (BRASIL, 1992), considerando a porcentagem de germinação (plântulas que se apresentavam bem formadas e sem sintomas ou sinais de contaminação por microorganismos), de plântulas anormais (com menor desenvolvimento e/ou com estruturas deterioradas e danificadas) e de sementes não germinadas (mortas e duras), com base em BRASIL (1992). Em conjunto com o teste de germinação, foi considerada a porcentagem de plântulas normais da primeira contagem e realizado o cálculo do índice de velocidade de germinação, com base em NAKAGAWA (1999). Os dados obtidos foram submetidos à análise de variância, e os obtidos em porcentagem foram transformados em arc sen $(\mathrm{x} / 100)^{1 / 2}$, quando necessário. Nas tabelas encontram-se os dados originais. As médias foram comparadas pelo teste Tukey, a $5 \%$ de probabilidade.

\section{RESULTADOS E DISCUSSÃO}

As análises com prospecção química e a análise por métodos físicos (IV e RMN) indicaram a presença de esteroides, triterpenoides e glicerídeos no extrato de arilo com diclorometano (AD) e de carboidratos no extrato de arilo com metanol (AM). Nesses dois extratos, não foi detectada a presença de alcaloides, saponinas, depsídios e depdisonas, flavonoides, catequinas e derivados de cumarina (Tabela 1). Há provável presença de açúcares redutores e de polissacarídeos no extrato AD pelo processo químico (Tabela 1), mas esta não foi confirmada pelos espectros. A análise dos espectros das frações desse extrato permitiu identificar a presença de esteroides, triterpenoides e triglicerídeos, constituintes pertencentes à classe dos lipídeos (VOET et al., 2001). $\mathrm{O}$ espectro no infravermelho do $\mathrm{AD}$ apresentou sinais de estiramento O-H $\left(3423 \mathrm{~cm}^{-1}\right)$, estiramento C-H, de $\mathrm{CH}_{2}$ e $\mathrm{CH}_{3}\left(2930-2857 \mathrm{~cm}^{-1}\right)$, estiramento de dupla ligação $\left(1646 \mathrm{~cm}^{-1}\right)$, além de sinais de confirmação de $\mathrm{CH}_{2}, \mathrm{CH}_{3}$ (1462 e 1377, deformação de C-H) e deformação axial de C-O (1252-1060 $\left.\mathrm{cm}^{-1}\right)$ (Figura 1a), que são compatíveis com estruturas de terpenoides. Essas classes de metabolitos foram confirmadas pelos sinais detectados no espectro de $\mathrm{RMN}{ }^{1} \mathrm{H}$ : os sinais entre 0,6 e $1,0 \delta$ representam os grupos metílicos; os sinais 1,0-2,0 0 , os hidrogênios de $\mathrm{CH}_{2}$ e $\mathrm{CH}$; os sinais $1,6-2,3 \delta$,

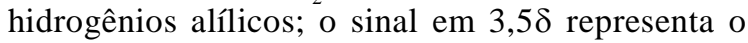
hidrogênio ligado no carbono oxigenado; e o sinal em $5,3 \delta$ representa o hidrogênio da dupla ligação. Os terpenoides desempenham funções hormonais, são inibidores do crescimento e de pigmentos, constituintes da cadeia de transporte de elétrons e atuam também no

Tabela 1 - Classes das substâncias detectadas nos extratos do arilo de maracujazeiro amarelo, com diclorometano (AD) e metanol (AM).

\begin{tabular}{|c|c|c|c|c|c|c|}
\hline \multirow[b]{2}{*}{ Classes de metabolitos } & \multicolumn{3}{|c|}{ 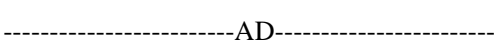 } & \multicolumn{3}{|c|}{ 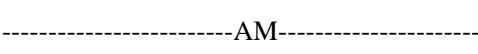 } \\
\hline & $\begin{array}{l}\text { Avaliação } \\
\text { química }\end{array}$ & IV & RMN & $\begin{array}{l}\text { Avaliação } \\
\text { química }\end{array}$ & IV & RMN \\
\hline Alcaloides & - & - & - & - & - & - \\
\hline Saponinas & - & - & - & - & ? & - \\
\hline Esteroides e Triterpenoides & + & + & + & - & - & - \\
\hline Depsídios e Depsidonas & - & - & - & - & - & - \\
\hline Flavonoides & - & - & - & - & - & - \\
\hline Catequinas & - & - & - & - & - & - \\
\hline Derivados de Cumarina & - & - & - & - & - & - \\
\hline Açúcares redutores & + & - & - & + & + & + \\
\hline Polissacarídios & + & - & - & - & - & + \\
\hline Ácidos orgânicos & - & - & - & + & + & - \\
\hline Glicerídeos & - & + & + & - & - & - \\
\hline
\end{tabular}




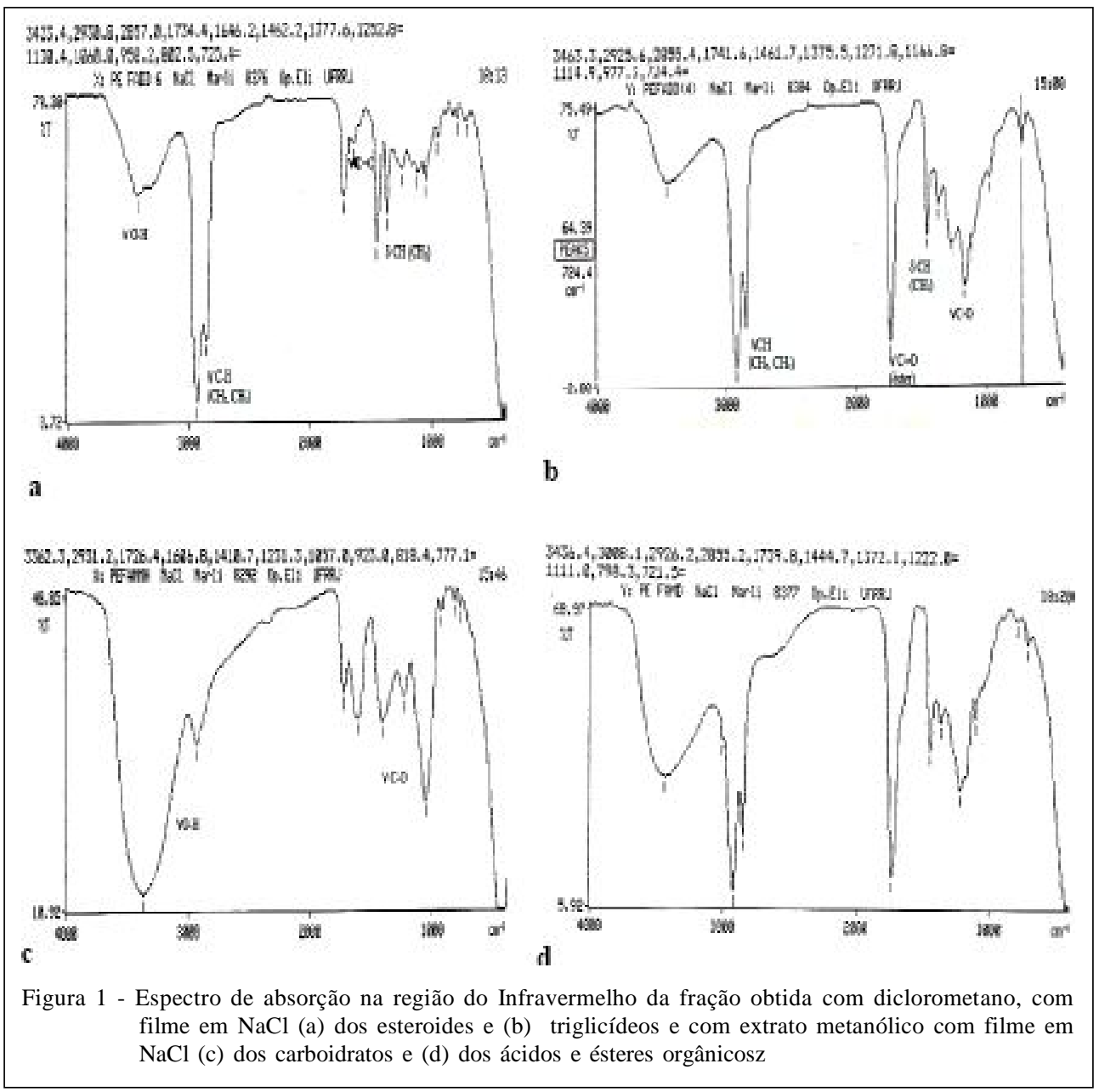

transporte de moléculas através da membrana (CASTRO et al., 2001). Por outro lado, os esteroides são importantes componentes de membranas, onde eles estabilizam as caudas dos fosfolipídios, podendo também funcionar como hormônios, tais como um grupo de derivados esteroides chamados brassinas, que promovem o crescimento de certos caules (CASTRO et al., 2001). As frações dos sinais revelam que há mistura de substâncias. Assim, essas constatações confirmam os resultados encontrados pela prospecção química (Tabela 1).

Não foram realizados testes químicos específicos para glicerídeos, mas, com a análise do espectro de $\mathrm{RMN}{ }^{1} \mathrm{H}$, foi possível detectar com segurança a presença triglicerídeos contendo unidade acila saturada e insaturada e, inclusive, com metileno entre duas ligações duplas (MDB). As informações obtidas com o espectro de infravermelho confirmaram a presença de glicerídeos, apresentando bando forte em 2925 e $2853 \mathrm{~cm}^{-1}$ (estiramento $\mathrm{C}-\mathrm{H}$ de $\mathrm{CH}_{2}$ e $\mathrm{CH}_{3}$ ), banda forte em $1741 \mathrm{~cm}^{-1}$, típica de estiramento de carbonila de ésteres. Essa função foi confirmada pela banda de estiramento C-O em 1271-1114cm $\mathrm{cm}^{-1}$ (Figura 1b). O alargamento do sinal da carbonila e do sinal de vibração axial de grupo metileno e metínico confirma a presença de ligação dupla. O sistema MDB é semelhante ao ácido linoleico $\left(\mathrm{C}_{18: 2}(9,12)\right)$ e aracdônico $\left(\mathrm{C}_{20: 4}(5,8,11,14)\right)$. A análise dos espectros de infravermelho e $\mathrm{RMN}{ }^{1} \mathrm{H}$ do extrato metanólico permitiu identificar a presença de carboidratos e ácidos graxos nesse material. Os sinais entre 2,5-4.5ppm são compatíveis com sinais de prótons de carbonos carbinólicos, e o sinal 4,7 representa sinais de prótons de carbono anomérico de açúcar (Figura 1c). A presença de ácidos graxos foi detectada pelos sinais em 2500$3360,1726,1606,1231 \mathrm{~cm}^{-1}$, no espetro de infravermelho (Figura 1d). De acordo com VOET et al. (2001), os triglicerídos possuem três cadeias de ácidos graxos, e os resíduos desses ácidos são os de C16 e C18: ácidos palmítico, oléico, linoleico e esteárico, que são 
insaturados. CASTRO et al. (2001) mencionam que em torno de $75 \%$ dos ácidos graxos são insaturados, podendo ser encontrados como constituintes da membrana celular. Já os ácidos graxos que são estocados no citoplasma das células das sementes possuem função de reserva energética. Segundo RAVEN et al. (2001), os carboidratos ou sacarídeos constituem as moléculas orgânicas mais abundantes na natureza, e alguns polissacarídeos funcionam como formas de armazenamento de açúcar, outros são importantes compostos estruturais. O dissacarídeo mais abundante é a sacarose, principal forma pela qual os carboidratos são transportados nas plantas (VOET et al., 2000). Contudo, certos polissacarídeos da parede celular, as oligossacarinas, podem funcionar como hormônios, regulando o crescimento e o desenvolvimento da planta (RAVEN et al., 2001).

$\mathrm{Na}$ tabela 2, pode-se observar que as sementes de alface apresentaram os maiores valores de germinação quando avaliadas em papel umedecido com água destilada, com ou sem tween. Quando foi utilizado o extrato à base de metanol (AM), foi verificada redução acentuada da germinação, $67 \%$ de plântulas anormais e 10\% de sementes não germinadas. Assim, esse extrato pode ter contribuído para retardar o processo de germinação, como constatado pela elevada porcentagem de plântulas anormais com menor desenvolvimento (PAD). Esses resultados provavelmente estão relacionados à presença de carboidratos nesse extrato (Tabela 1), que pode ter diminuído a disponibilidade de água para as sementes, retardando consequentemente o processo germinativo. Em soja, BRACCINI et al. (1996) e, em girassol, BARROS \& ROSSETTO (2009b) observaram que potenciais hídricos muito negativos influenciaram a absorção de água pelas sementes, inviabilizando a sequência de eventos que culminam com a emergência das plântulas. Assim, com o aumento da concentração das soluções osmóticas, ocorre menor desenvolvimento meristemático e maior atraso na germinação, causado pelo prolongamento da fase estacionária do processo de embebição, devido à redução da síntese ou da atividade das enzimas hidrolíticas necessárias à germinação (SILVA et al., 2006; CAMPOS \& ASSUNÇÃO, 1990). Também pôde ser observado o desenvolvimento de fungos patogênicos nessas sementes após terem sido germinadas na presença de AM, provavelmente utilizando esses carboidratos como substrato. Para FERREIRA et al. (2004), é preciso recomendar o controle do $\mathrm{pH}$ e da concentração de extratos brutos durante os testes realizados no laboratório, pois pode haver neles a presença de substâncias como açúcares, aminoácidos e ácidos orgânicos, os quais influenciam a concentração iônica e são osmoticamente ativos.

No entanto, quando foi usado o extrato obtido com diclorometano (AD), foi verificada redução acentuada da germinação, $14 \%$ de plântulas anormais e $84 \%$ de sementes não germinadas (Tabela 2). Esse extrato pode ter contribuído para impedir ou inviabilizar o processo germinativo, como pode ser constatado pela elevada porcentagem de sementes não germinadas (mortas ou duras). Esses resultados podem estar relacionados à exposição das sementes a potenciais hídricos muito negativos, que impossibilitam a absorção de água pelas sementes, assim como constatado por HADAS (1976) para leguminosas. Além disso, resultados semelhantes também foram observados para sementes de girassol (BARROS \& ROSSETTO, 2009), em que as sementes não germinaram a -0,9MPa. Nesse extrato, a presença de moléculas hidrofóbicas, tais como os triglicerídeos insaturados (Tabela 1), provavelmente dificultou a embebição das sementes, formando uma barreira na entrada de água ou, ainda, a presença de esteroides, que são substâncias que podem funcionar como

Tabela 2 - Dados médios de porcentagem de germinação(G), de plântulas normais da primeira contagem (PC), de plântulas anormais deformadas (PAD) e de sementes não germinadas (SNG), bem como de índice de velocidade de germinação (IVG), obtidos de sementes de alface (Lactuca sativa) submetidas aos extratos de arilo de maracujazeiro amarelo.

\begin{tabular}{llllll}
\hline Tratamentos & $\mathrm{G}$ & $\mathrm{PC}$ & IVG & PAD & SNG \\
\hline água destilada & $89 \mathrm{a}$ & $87 \mathrm{a}$ & $21,97 \mathrm{a}$ & $10 \mathrm{~b}$ & $2 \mathrm{~b}$ \\
água destilada + tween & $78 \mathrm{a}$ & $62 \mathrm{~b}$ & $17,80 \mathrm{a}$ & $19 \mathrm{~b}$ & $3 \mathrm{~b}$ \\
Extrato de arilo à base de diclorometano + tween & $3 \mathrm{c}$ & $0 \mathrm{c}$ & $0,39 \mathrm{c}$ & $14 \mathrm{~b}$ & $84 \mathrm{a}$ \\
Extrato de arilo à base de metanol + tween & $22 \mathrm{~b}$ & $0 \mathrm{c}$ & $3,21 \mathrm{~b}$ & $67 \mathrm{a}$ & $10 \mathrm{~b}$ \\
DMS & 0,332 & 0,004 & 0,099 & 0,444 & 0,411 \\
CV $(\%)$ & 21,45 & 0,42 & 16,64 & 41,96 & 47,30 \\
\hline
\end{tabular}

Médias não seguidas pela mesma letra na coluna diferem entre si pelo teste Tukey, com nível de 5\% de probabilidade. 
hormônios, tais como as brassinas (RAVEN et al., 2001), pode ter desbalanceado os hormônios existentes nas sementes, competindo pelo sítio ativo e/ou inibindo a ação dos hormônios necessários para a germinação. De acordo com esses mesmos autores, existem evidências de que as plantas produzem estrógeno, um dos hormônios sexuais de mamíferos, porém o seu papel na planta é desconhecido. Trabalhos futuros podem ser efetuados visando a avaliar o efeito dos esteroides. Para isso, pode-se usar o sitosterol e/ou estigmasterol, que são abundantes em plantas, nessa avaliação. Além disso, não se deve descartar a possível ação dos ésteres derivados do ácido linoleico. O sistema insaturado, nessas cadeias carbônicas, pode captar radicais e formar outros metabólitos especiais que possam interferir na germinação.

Quando foi avaliado o vigor das sementes expostas aos extratos, foi constatado que houve ausência de plântulas normais na primeira contagem do teste de germinação. além de ter havido redução dos valores na presença do tween empregado. Já pelo teste de índice de velocidade de germinação (IVG) foi verificado que ambos os extratos promoveram redução do vigor. No entanto, o extrato à base de diclorometano foi o que proporcionou maior redução da velocidade de germinação. De acordo com THANOS \& SKORDILIS (1987), trabalhando com pinus, quando as sementes são submetidas ao estresse osmótico, a velocidade de germinação é mais lenta, enquanto a porcentagem de germinação é inibida em potenciais mais elevados.

\section{CONCLUSÃO}

Foram encontrados terpenos, esteroides e glicerídeos como constituintes dos extratos menos polares e mistura de carboidratos no extrato de maior polaridade. $\mathrm{O}$ extrato de arilo obtido com dicloro apresenta esteroides e triterpenoides que inibe a germinação das sementes de maracujá amarelo. O extrato metanólico apresenta acúcares redutores e reduz a germinação das sementes. Essas substâncias certamente interferiram diretamente ou indiretamente na absorção de água, inibindo a germinação da semente.

\section{REFERÊNCIAS}

BARROS, C.S.; ROSSETTO, C.A.V. Condicionamento fisiológico de aquênios de girassol. Ciência Rural, v.39, n.6, p.1667-1675, 2009. Disponível em: <http://www.scielo.br/ scielo.ph p s cript=sci_arttext \& pid=S 0103 $84782009000600006 \& \operatorname{lng}=\mathrm{pt} \& \mathrm{nrm}=\mathrm{i}$ so\&tlng=pt $>$. Acesso em: 15 jun. 2010. doi: 10.1590/S0103-84782009000600006.
BÖCKER, J. Spektroskopie. Wurzburg: Vogel, 1997. 145p.

BRACCINI, A.L. et al. Germinação e vigor de sementes de soja sob estresse hídrico induzido por soluções de cloreto de sódio, manitol e polietilenoglicol. Revista Brasileira de Sementes, v.18, n.2, p.10-16, 1996.

BRASIL. Ministério da Agricultura e Reforma Agrária. Regras para análise de sementes. Brasília: SNDA/DNDV/CLAV, 1992. 365p.

CARDOSO, G.D. et al. Desenvolvimento de mudas de maracujazeiro amarelo obtidas de sementes extraídas por fermentação. Revista Brasileira de Fruticultura, v.23, n.3, p.639-642, 2001. Disponível em: <http://www.scielo.br/ scielo.php? script $=\mathrm{sci}_{-}$art text \& pid = S $0100-$ $29452001000300039 \& \operatorname{lng}=\mathrm{pt} \& \mathrm{nrm}=\mathrm{iso} \& \ln \mathrm{g}=\mathrm{pt}>$. Acesso em: 28 nov. 2009. doi: 10.1590/ S0100-29452001000300039.

CAMPOS, I.S.; ASSUNÇÃO, M.N. Estresse salino e hídrico na germinação e vigor de sementes de arroz. Pesquisa Agropecuária Brasileira, v.25, n.6, p. 857-862, 1990.

CARVALHO, N.M.; NAKAGAWA, J. Sementes: ciência, tecnologia e produção. Jaboticabal: FUNEP, 2000. 588p.

CASTRO, H.G. et al. Contribuição ao estudo das plantas medicinais: metabólitos secundários. Visconde do Rio Branco: Suprema, 2001. 104p.

COSTA, A.F. Farmacognosia. Lisboa: Fundação Calouste Gulbenkian, 1972. V.II e III.

FERREIRA, A.G. Interferência, competição e alelopatia. In: FERREIRA, A.G.; BORGHETTI, F. Germinação: do básico ao aplicado. Porto Alegre: Artmed, 2004. p.251-262.

GEMMELL, A.R. Anatomia do vegetal em desenvolvimento. São Paulo: EPU/EDUSP, 1981. 73p.

GHERARDI, E.; VALIO, I.F.M. Occurence of promoting and inhibitory substances in the seed arils of Carica papaya L. Journal of Horticultural Science, v.51, n.1, p.1-14, 1976.

HADAS, A. Water uptake and germination of leguminous seeds under changing external water potencial in osmotic solution. Journal Express Botany, v.27, p.480-489, 1976. Disponível em: <http://www.scielo.br/scieloOrg/php/reflinks.php?refpid=S0101$3122200700010001400010 \& \mathrm{p} \mathrm{id}=\mathrm{S} 0101$ $31222007000100014 \& \operatorname{lng}=e n>$. Acesso em: 28 nov. 2009. doi: $10.1093 / \mathrm{jxb} / \mathrm{S} 0101-31222007000100014$.

LOPES, J.C. et al. Germinação e vigor de plantas de maracujazeiro amarelo em diferentes extratos de maturação do fruto, arilo e substrato. Ciência e Agrotecnologia, v.31, n.5, p. 1340-1346, 2007. Disponível em: <http://www.scielo.br/ scielo.php? script=sci_arttext \& pid=S 1413 $70542007000500010 \& \operatorname{lng}=\mathrm{pt} \& \mathrm{nrm}=\mathrm{iso} \& \mathrm{t} \operatorname{lng}=\mathrm{pt}>$. Acesso em: 15 jun. 2010. doi: 10.1590/S1413-70542007000500010.

MATOS, F.J.A. Introdução à fitoquímica experimental. Fortaleza: UFC, 1997. 141p.

MORLEY-UNKER, M.J.S. Some aspects of seed dormancy with reference to Passiflora spp. and other tropical and subtropical crops. Londres: Univ. of London, 1974. 43p. 
NAKAGAWA, J. Testes de vigor baseados na avaliação das plântulas. In: VIEIRA, R.D.; CARVALHO, N.M. de. (Eds). Testes de vigor em sementes. Jaboticabal: FUNEP, 1999. p.49-86.

PEREIRA, C.E. et. al. Determinação de inibidores da germinação no endosperma de sementes de café (Coffea arábica L.). Revista Brasileira de Sementes, v.24, n.1, p.306-311, 2002 .

PEREIRA, K.J.C.; DIAS, D.C.F.S. Germinação e vigor de sementes de maracujá-amarelo (Passiflora edulis Sims. F. flavicarpa Dg.) submetidas a diferentes métodos de remoção de mucilagem. Revista Brasileira de Sementes, v.22, n.1, p.288-291, 2000 .

RAVEN, P.H. et al. Biologia vegetal. New York: Guanabara Koogan, 2001. 906p.

REYES, M.N. et al. Detecting endogenous growth regulators on the sarcotesta, sclerotesta, endosperm and embry by paper chromatography on fresh and old seeds of two papaya varieties. Journal Agricultural University of Puerto Rico, v.64, n.2, p.167-172, 1980. Disponível em: <http://www.scielo.br/scieloOrg/ p h p / r ef li n k s.php? ref pi d = S 0101 $3122200700030002200020 \&$ pid = S 0101 - 31222007000300022\&lng=en>. Acesso em: 28 nov. 2009. doi: 10.1590/S0101-31222007000300022.

SÃO JOSÉ, A.R; NAKAGAWA, J. Efeitos da fermentação e secagem na germinação de sementes de maracujá amarelo. Revista Brasileira de Sementes, v.9, n.2, p.35-43, 1987.

SILVA, J. B. et al. Desempenho de sementes de soja submetida a diferentes potenciais osmóticos em polietilenoglicol. Ciência Rural, v.36, n.5, p.1634-1637, 2006. Disponível em: <http:// www.scielo.br/scielo.php?script $=$ sci_arttext \&pid $=$ S0103$84782006000500047 \& \operatorname{lng}=$ pt\&nrm=iso>. Acesso em: 15 jun. 201. doi: 10.1590/S0103-84782006000500047.

THANOS, C.A.; SKORDILIS, A. The effects of light temperature and osmotic stress on the germination of Pinus halepenisis and $\boldsymbol{P}$. brutia seeds. Seed Science and Technology, v.15, n.16, p.163-174, 1987.

VOET, D. et al. Fundamentos de bioquímica. Porto Alegre: ARTMED, 2001. 113p.

WALL, M.E. Steroidal saponenins VII - Survey of plants for steroidal saponenins and other constituints. Journal of the American Pharmaceutical Association, v.43, n.1, p.1-7, 2006. Disponível em: <http://www3.interscience.wiley.com/ journal/113371246/abstract $>$. Acesso em: 28 nov. 2009. doi:10.1002/jps.3030430102. 